\title{
Highly selective and stable Zn-Fe/ZSM-5 catalyst for aromatization of propane
}

\author{
Gbenga Godwin Oseke ${ }^{1}$ Abdulazeez Yusuf Atta ${ }^{1} \mathbb{D} \cdot$ Bello Mukhtar $^{1} \cdot$ Baba Yakubu Jibril $^{1}$. \\ Benjamin Olorunfemi Aderemi ${ }^{1}$
}

Received: 1 February 2020 / Accepted: 8 May 2020 / Published online: 18 May 2020

(c) The Author(s) 2020

\begin{abstract}
Light alkane aromatization for aromatic compound production, used in petrochemical industries is an attractive area of research. The effect of second metal co-impregnation was investigated in stabilizing zinc on ZSM-5 in aromatization of propane. HZSM-5 was modified with zinc and iron metal by co wet-impregnation and characterized using XRF, XRD, BET, $\mathrm{N}_{2}$-adsorption, FTIR, FTIR-Pyridine, SEM, TEM, $\mathrm{H}_{2}$-TPR and XPS. The effect of different loadings of Iron on $\mathrm{Zn} /$ ZSM-5 was investigated on acidity, aromatic yield, product distribution and aromatization performance. Performance test was conducted in a fixed bed reactor at $540{ }^{\circ} \mathrm{C}$, one atmosphere. GHSV of $1200 \mathrm{~mL} / \mathrm{g}$-h. Co-impregnation of $\mathrm{Zn}$ with $\mathrm{Fe}$ improved the catalytic activity and aromatic yield for $10 \mathrm{~h}$ time on stream as compared to parent HZSM- 5 and Zn/ZSM-5 of very low aromatic yield and propane conversion. Impregnation of $\mathrm{Zn}$ as the dehydrogenating metal on HZSM-5 steadily increased aromatic yield from 5\% on HZSM-5 to $25 \%$ and was steadily dropped to $20 \%$ after $10 \mathrm{~h}$ TOS. The co-impregnation of iron of 1-3 wt\% loading as the second metal for zinc stability with $2 \mathrm{wt} \% \mathrm{Zn}$ on ZSM-5 improved propane conversion and aromatic yield to $55 \%$ for the $10 \mathrm{~h}$ TOS. This further enhanced aromatic product distribution and minimized light gases.
\end{abstract}

Keywords Propane aromatization $\cdot$ Bimetallic $\cdot$ HZSM-5 zeolite $\cdot$ Co-impregnation $\cdot$ Zn-Fe/ZSM-5

\section{Introduction}

The use of light alkanes as industrial feedstock for petrochemicals and chemical plants has made its studies for aromatization a research interest both in industries and academia. Alkanes alongside other hydrocarbons are found in large deposits in natural gas reservoirs, gas condensate wells and as bye-products of petroleum refining operations. Conversion of propane into higher value chemicals via aromatization is of major importance [1].

ZSM-5 has unique structural pores that favor migration of aromatics due to their similarities in pore size [1-3], which enhances its high shape selectivity towards aromatics. Use of parent ZSM-5 as reported in literatures showed high coking and low selectivity towards aromatics as its limitations. Many works have been published towards mitigating this limitation via use of promoters, changing the silica

Abdulazeez Yusuf Atta

zeezoatta@gmail.com; ayatta@abu.edu.ng

1 Chemical Engineering Department, Ahmadu Bello University, Zaria, Nigeria alumina ratio to optimize the number and density of active sites, modifying the surface through hierarchical catalyst synthesis, shortening the path length via synthesis of nanocrystalline ZSM-5 etc [4-8].

Screening of several metals as dehydrogenating promoters have been studied on ZSM-5 support matrix to improve selectivity towards aromatics. Zinc, platinum and gallium metals have proven to be highly dehydrogenating though with some shortcomings to their use. Platinum metal is very expensive and prone to hydrogenolysis. The high cost of gallium metal alongside its hazardous nature to human health had cautioned its use as dehydrogenating metal. The high cost of gallium metal alongside its hazardous nature to human health had cautioned its use as dehydrogenating metal. Zinc metal is relatively cheap, readily available for procurement, highly dehydrogenating as bifunctional sites on ZSM-5 for light alkane aromatization but loses its stability at reaction temperature and long hour time on stream operations. In the case of metals on zeolites, it has also been reported that cations from transition metals can interact both with the Zinc atoms and the zeolitic structure, which helps 
to diminish or minimize the migration of metallic particles [9-19].

This present study investigated the co-impregnation effect of zinc metal as active site with different loading of iron on ZSM-5 for propane aromatization in fixed bed reactor.

\section{Experimental section}

\section{Catalyst preparation}

$\mathrm{NH}_{4}$-ZSM5 ( $\left.\mathrm{Si} / \mathrm{Al}=50\right)$ was sourced commercially from Sigma Aldrich and calcined to obtain HZSM-5 at $550{ }^{\circ} \mathrm{C}$ for $5 \mathrm{~h}$. Aqueous solutions containing of $\mathrm{Zn}\left(\mathrm{NO}_{3}\right)_{2}$ as precursor for $2 \mathrm{wt} \% \mathrm{ZnO}$ and $\mathrm{Fe}\left(\mathrm{NO}_{3}\right)_{2}$ as precursor for 1-3 wt $\%$ of $\mathrm{Fe}_{2} \mathrm{O}_{3}$ were co-impregnated by introducing them at the same time dropwise on solution of H-ZSM5 catalysts with stirring for effective mixing, and heated to dryness at $70{ }^{\circ} \mathrm{C}$. The catalysts were further dried at $80{ }^{\circ} \mathrm{C}$ for $16 \mathrm{~h}$ and then calcined by temperature programmed furnace at $550{ }^{\circ} \mathrm{C}\left(4^{\circ} \mathrm{C}\right.$ per minute ramping $)$ for $5 \mathrm{~h}$. The reactions for iron(II) oxide and zinc oxide conversion from their precursor hexahydrates are given in Eqs. (1) and (2).

$$
\mathrm{Zn}\left(\mathrm{NO}_{3}\right)_{2} \cdot 6 \mathrm{H}_{2} \mathrm{O} \rightarrow \mathrm{ZnO}+2 \mathrm{NO}_{2}+1 / 2 \mathrm{O}_{2}+6 \mathrm{H}_{2} \mathrm{O}
$$

$2 \mathrm{Fe}\left(\mathrm{NO}_{3}\right)_{2} \cdot 6 \mathrm{H}_{2} \mathrm{O} \rightarrow 2 \mathrm{Fe}_{2} \mathrm{O}_{3}+4 \mathrm{NO}_{2}+1 / 2 \mathrm{O}_{2}+12 \mathrm{H}_{2} \mathrm{O}$

\section{Characterization}

FTIR spectra measurement was performed using Shimadzu FTIR-8400s spectrophotometer (64 scans, $4 \mathrm{~cm}^{-1}$ ) to obtain the characteristic spectra functional group. Pyridine-FTIR was used to identify and quantify the presence of Brønsted and Lewis acidity using Shimadzu FTIR-8400s spectrophotometer. Catalyst crystallinity was determined using the XRD patterns obtained using MiniFlex II X-ray diffractometer by Rigaku (Copper $\mathrm{K} \alpha$ rays, 40 kilovolts and 40 mill ampere, $\mathrm{K}_{\text {alpha1 }}=1.540598, \mathrm{~K}_{\text {alpha2 }}=1.544426$ and $\mathrm{K}_{\text {beta }}=1.392218$, $2 \mathrm{q}$ from $3^{\circ}$ to $70^{\circ}$ at scanning speed of $12^{\circ}$ per minutes). $\mathrm{N}_{2}$-adsorption was conducted using Micrometrics ASAP2020 machine at $77 \mathrm{~K}$. Catalyst was degassed in a vacuum for $10 \mathrm{~h}$ at $300{ }^{\circ} \mathrm{C}$. BET model was used to calculate the specific area of catalyst surface from the nitrogen isotherm. Analysis from t-plot were used to measure the micropore volumes and areas [11, 12]. Morphology of the catalyst surface were obtained using SEM Machine Hitachi S-4800 15 kilovolts. Transmission electron microscopy(TEM) images of the catalysts were obtained on a FEI Tecnai G2 Spirit STEM microscope (740 kilovolts using a carbon coated holey film on catalysts). Hydrogen-TPR plots of catalysts were conducted using Micrometrics equipment, at $\beta=10^{\circ} \mathrm{C} /$ $\mathrm{min} ; w=75 \mathrm{mg} ; F=50 \mathrm{ml} / \mathrm{min}$ and $\Delta T=100-800{ }^{\circ} \mathrm{C}$. XPS spectra were obtained with Axis Ultra Dld X-ray photoelectron spectrometer monochromatized micro-focused at AlKalpha-radiation, 15 kilovolts, $30 \mathrm{~mA}(450 \mathrm{~W})$.

\section{Catalytic activity evaluation}

Activity tests of the prepared catalysts were carried out in a stainless-steel fixed bed continuous flow reactor with internal diameter of $9 \mathrm{~mm} .0 .5 \mathrm{~g}$ of the catalyst was mixed with $0.5 \mathrm{~g}$ of silica glass beads. The catalysts were degassed under inert nitrogen flow environment as the temperature rose through the reactor to $540{ }^{\circ} \mathrm{C}$ for $2 \mathrm{~h}$ before the reaction. Propane was introduced to flow through the reactor. The reaction was carried out at $540{ }^{\circ} \mathrm{C}$ and gas hourly space velocity (GHSV) of $1200 \mathrm{ml} / \mathrm{g}$-h, pure propane and nitrogen of ratio 1:2 under atmospheric pressure. The products flowed from the lagged reactor product line to keep it in gaseous phase before entering the GC. The products from the reactor were analyzed in-situ using an online Buck Scientific gas chromatographer GC 910 attached to the reactor. The GC had thermal conductivity detector (TCD) with a Mol sieve 13X packed column for hydrogen, nitrogen and hydrogen detection and a flame ionization detector (FID) connected to Restek MTX1 and HAYESEP D oven packed column for hydrocarbon detection and analysis. Aromatic compounds and other products yield and selectivity were calculated based on the relative ratio of each product with respect to total moles of carbon containing products from the reactor.

\section{Results and discussion}

This work aimed at studying the effect of the iron second metal co-impregnation with zinc on ZSM-5. So comparison was made on parent ZSM-5, Zn/ZSM-5 and Zn-Fe/ZSM-5 catalyst of different iron loading.

Figure 1 shows the FTIR spectra of HZSM-5 and the corresponding zinc and iron metal loaded catalysts. Basic HZSM-5 peaks were featured on the modified catalyst as they were on HZSM-5. All the characteristic peaks corresponding to parent HZSM-5 were present on the metal modified catalysts irrespective of loading. Peak intensities at 450 and $550 \mathrm{~cm}^{-1}$ depicted $\mathrm{T}-\mathrm{O}$ bend and double- 5 ring of crystalline of ZSM-5 while 1100 and $1225 \mathrm{~cm}^{-1}$ correspond to internal and external asymmetric stretch respectively. The peaks at 3400 and $1700 \mathrm{~cm}^{-1}$ were double bond stretching and bending vibration of hydroxyl $\left(\mathrm{OH}^{-}\right)$group of physically absorbed water on the surface of HZSM-5 zeolite $[13-15,20]$. 


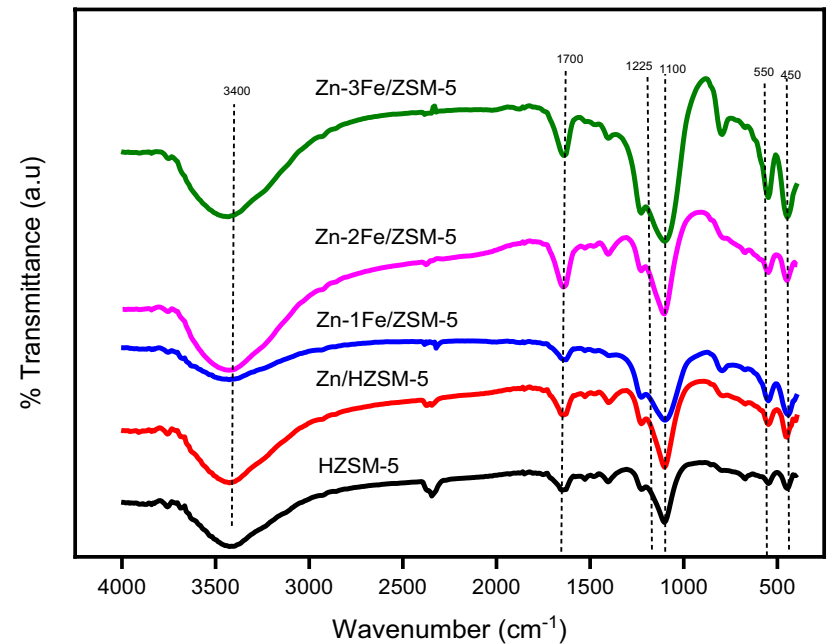

Fig. 1 FTIR spectra of ZSM-5 catalysts

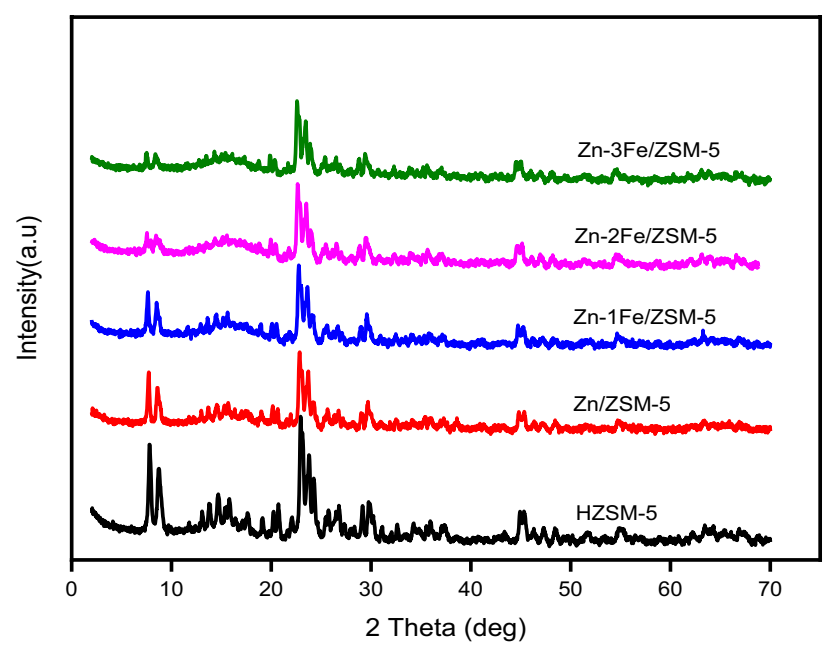

Fig. 2 XRD of ZSM-5 catalysts

The X-ray diffractogram of the parent HZSM-5 with the metal modified catalysts were presented in Fig. 2. The loading of $\mathrm{Zn}$ and $\mathrm{Fe}$ had no significant effect on the HZSM-5 structure as loading increased except for the suppressed peak as a result of metal impregnated on the zeolite surface. This indicate that ZSM-5 crystallinity was maintained and structure unaffected by metals. This further confirmed that all the catalysts had the five typical distinguishing diffraction peaks of ZSM-5 structure suggest that metal impregnation process did not visibly change the framework structure of parent HZSM-5. There were no characteristic peaks to denote the present of the impregnated metals because of low concentration of metal zeolite surface and pore [16-18]. The characteristic peaks of ZSM-5 were found though suppressed at $2 \theta=7.89^{\circ}$,

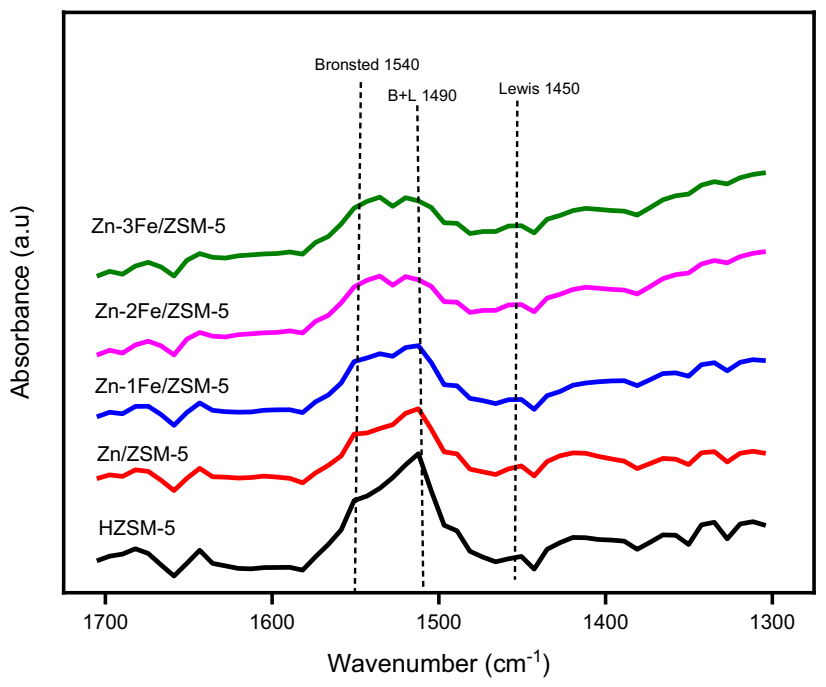

Fig. 3 Pyridine-FTIR of ZSM-5 catalysts

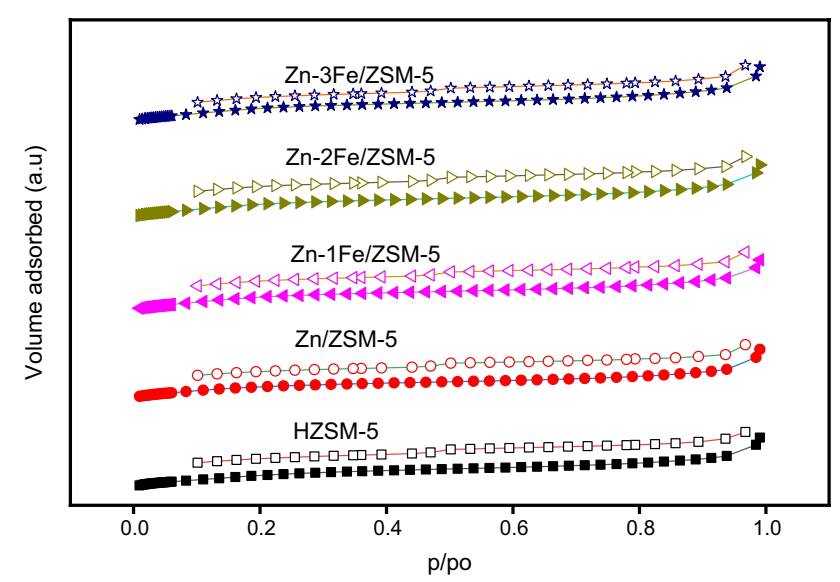

Fig. $4 \mathrm{~N}_{2}$-adsorption of ZSM-5 catalysts

$8.73^{\circ}, 14.82^{\circ}, 23.04^{\circ}, 23.86^{\circ}$, and $24.26^{\circ}$ at increased metal loading [19-24].

FTIR-Pyridine indicating the strength of the catalyst acidity with increase metal loadings was as shown in Fig. 3. It was observed that there were three major adsorption peaks of pyridine at approximately $1450 \mathrm{~cm}^{-1}, 1490 \mathrm{~cm}^{-1}$ and $1540 \mathrm{~cm}^{-1}$, which were assigned to the characteristic bands of LAS, the cocontribution of LAS and BAS, and BAS, respectively. It was generally observed that the Bronsted acidity decreased as metal loading increased on parent ZSM-5. This was due to replacement of Bronsted sites by the added metals on the surface of the catalyst having a significant effect on activity test for propane aromatization $[25,26]$.

Nitrogen adsorption and desorption isotherm plots were shown in Fig. 4 for all the prepared catalysts. All the plots for the catalysts exhibited a Type I isotherm with high 
level microporosity as revealed in the BET specific surface area. The summary of the surface area and micropore analysis is presented in Table 1. Addition of $\mathrm{Zn}$ to the parent HZSM-5 decreased the total surface area. The specific total surface area, micropore and mesopore surface area of the catalyst were lower than HZSM-5 zeolite. These changes were due to the deposition of large $\mathrm{Zn}$ particles on the external surface, which blocked both the meso- and micropore. Zn-Fe/ZSM-5, the micro and meso-surface and pore volume increased. This suggests that some $\mathrm{Fe}$ particles attached to the external acid sites on the ZSM-5 structure while some on the surface [8, 27-29].
The SEM and TEM images study of micro-structured zeolitic catalyst were presented in Fig. 5. The morphology of parent ZSM-5 a did not vividly change after the addition of metallic oxides as the $\mathrm{Zn}$ and $\mathrm{Fe}$ were co-impregnated on HZSM-5 as seen from a-c which are SEM images of HZSM5, Zn/ZSM-5 and Zn-Fe/ZSM-5 respectively. This implies that the metal addition had little influence on the surface morphology of HZSM-5 [30, 31]. The voids were filled on the TEM images as Fe aided even dispersion of Zinc on ZSM-5 matrix in Fig. 5d-f which also are TEM images of HZSM-5, Zn/ZSM-5 and Zn-Fe/ZSM-5 respectively.

The TPR profile in Fig. 6 obtained for HZSM-5 and $\mathrm{Zn} / \mathrm{ZSM}-5$ showed no peaks that could be attributed to

Table 1 Textural properties of ZSM-5 catalysts

\begin{tabular}{lllllll}
\hline Catalyst(s) & $\mathrm{S}_{\text {BET }}{ }^{\mathrm{a}}\left(\mathrm{m}^{2} / \mathrm{g}\right)$ & $\mathrm{S}_{\text {micro }}{ }^{\mathrm{c}}\left(\mathrm{m}^{2} / \mathrm{g}\right)$ & $\mathrm{S}_{\text {mesoc }}\left(\mathrm{m}^{2} / \mathrm{g}\right)$ & $\mathrm{V}_{\text {total }}^{\mathrm{b}}\left(\mathrm{cm}^{3} / \mathrm{g}\right)$ & $\mathrm{V}_{\text {micro }}{ }^{\mathrm{c}}\left(\mathrm{cm}^{3} / \mathrm{g}\right)$ & Pore width $(\mathrm{nm})$ \\
\hline HZSM-5 & 373.22 & 333.36 & 39.87 & 0.261 & 0.106 & 2.793 \\
Zn/ZSM-5 & 361.08 & 323.10 & 37.98 & 0.254 & 0.141 & 2.778 \\
Zn-1Fe/ZSM-5 & 386.10 & 346.70 & 39.40 & 0.266 & 0.156 & 2.760 \\
Zn-2Fe/ZSM-5 & 386.64 & 345.04 & 41.63 & 0.272 & 0.155 & 2.617 \\
Zn-3Fe/ZSM-5 & 379.93 & 336.85 & 43.08 & 0.276 & 0.153 & 2.610 \\
\hline
\end{tabular}

${ }^{\mathrm{a}}$ BET method

${ }^{\mathrm{b}}$ Volume adsorbed at $\mathrm{P} / \mathrm{Po}=0.99$

${ }^{c}$ t-plot method
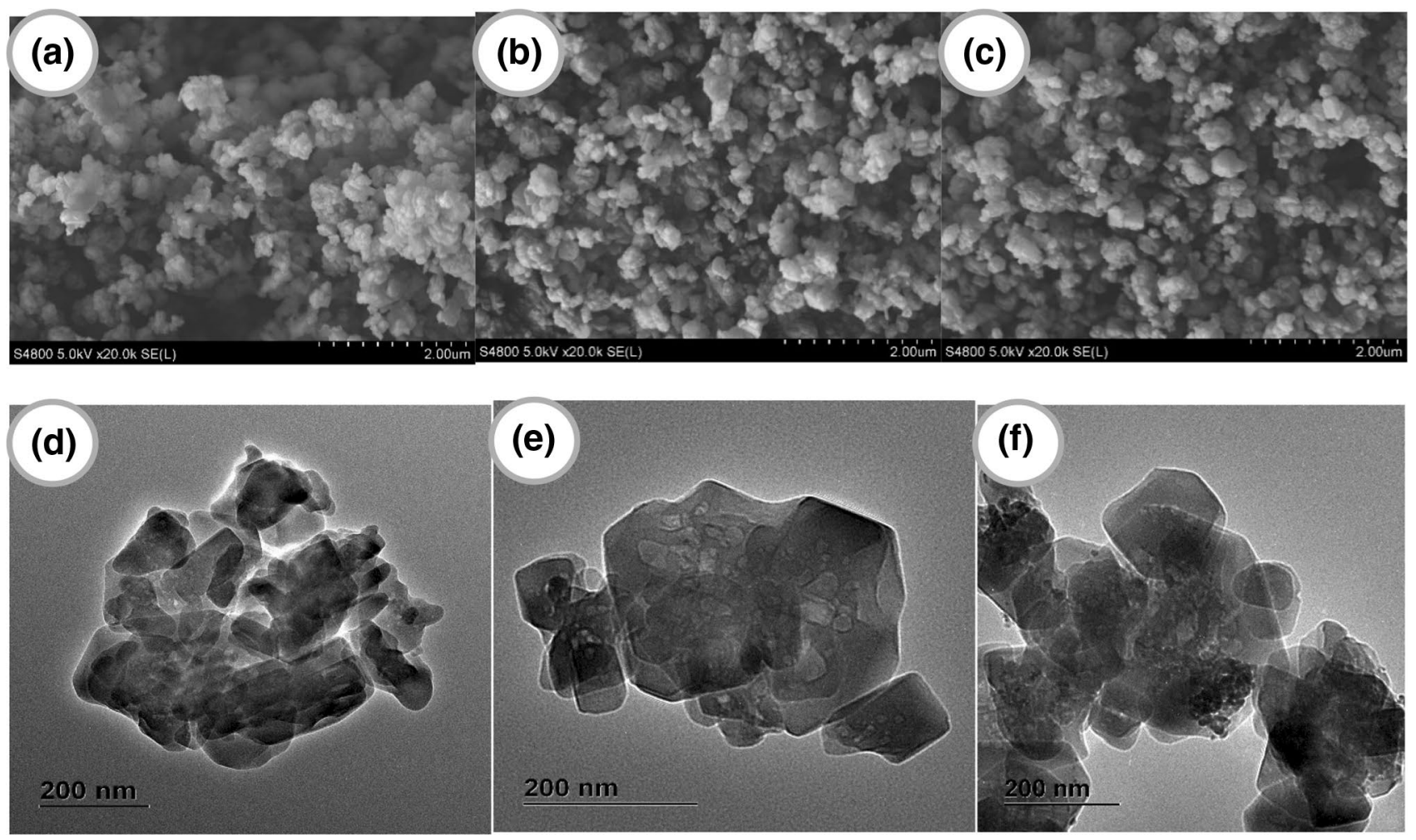

Fig. 5 SEM images of a HZSM-5, b Zn/ZSM-5 and $\mathbf{c}$ Zn-Fe/ZSM-5 and TEM images of $\mathbf{d}$ HZSM-5, b Zn/ZSM-5 and $\mathbf{f}$ Zn-Fe/ZSM-5 catalysts 


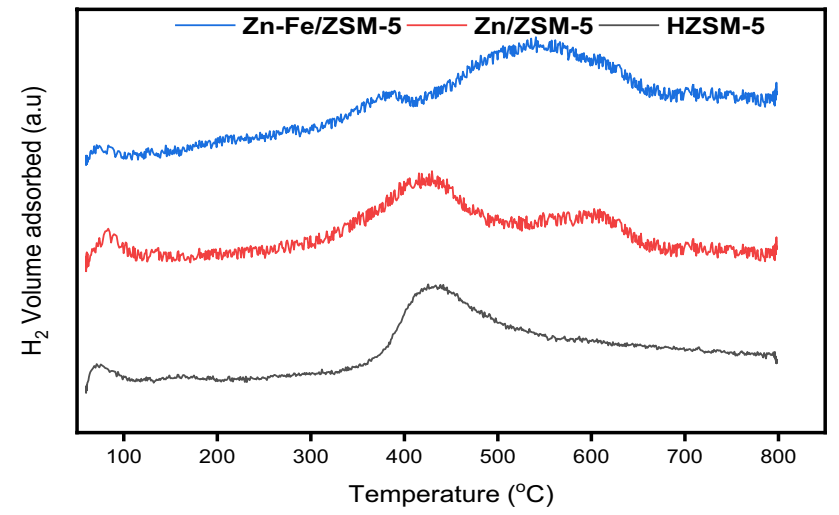

Fig. 6 TPR profile of ZSM-5 catalysts

$\mathrm{H}_{2}$-consumption. Fe/HZSM-5 contained double peaks [32], with maximum reducing temperature of $350{ }^{\circ} \mathrm{C}$ and $580{ }^{\circ} \mathrm{C}$, which indicated that the reduction takes place in two stages. $\mathrm{Zn}-\mathrm{Fe} / \mathrm{ZSM}-5$ had slight reduction around 390 and $560{ }^{\circ} \mathrm{C}$ $[24,33,34]$. It was suggested that a strong interaction between the metals led to shift in peak either to left or right from the normal single metal hydrogen-TPR thus enhancing formation of stable metal-metal alloy of Zn-Fe on ZSM-5. This also facilitated the reduction of hardly reducible metals like zinc. This occurrence could relate to the electronic interaction between $\mathrm{Zn}$ and $\mathrm{Fe}$. In broad view, the strongest metal-metal interface occurs in catalyst systems between a metal with its valence band almost or completely filled and another metal with its valence band almost empty. Thus, the rearrangement of charge moves the electrons from $\mathrm{Zn}$ into the interface region between $\mathrm{Zn}$ and $\mathrm{Fe}$ [35].

The XPS analysis was employed often to obtain the surface composition details and oxidation states of metals of industrial catalysts [36]. Figure 7 showed $\mathrm{Zn}^{2+}$ and $\mathrm{Fe}^{2+}$ oxidations states. HZSM-5 and Zn/HZSM-5 zeolite were characterized by XPS. Figure $7 \mathrm{c}$, the Fe 2p3/2 and Fe 2p1/2 XPS spectrum at 717.2 and $730.1 \mathrm{eV}$ respectively could be attributed to the $\mathrm{Fe}_{2} \mathrm{O}_{3}$ phase, which suggested that a portion of clusters loaded in the surface of $\mathrm{Zn}-\mathrm{Fe} / \mathrm{ZSM}-5$ were $\mathrm{Fe}_{2} \mathrm{O}_{3}$ species. The XPS spectra of $\mathrm{Zn} 2 \mathrm{p} 3 / 2$ and $\mathrm{Zn}$ 2p3/2 were observed at binding energy 1029 and $1051 \mathrm{eV}$ respectively in Fig. 7b for Zn-Fe/ZSM-5 and 1025 and 1048 for $\mathrm{Zn} / \mathrm{ZSM}-5$ in Fig. 7a. The lower binding energy of $\mathrm{Zn}$ $2 \mathrm{p} 3 / 2$ showed the $\mathrm{ZnO}$ clusters dispersed in the surface of zeolite and the higher $\mathrm{Zn} \mathrm{2p1/2} \mathrm{binding} \mathrm{energy} \mathrm{was} \mathrm{attrib-}$ uted to the $\mathrm{ZnOH}+$ species [25, 37]. Fe loading enhanced the dispersion of $\mathrm{ZnO}$ and increased the concentration of $\mathrm{ZnOH}+$ which was also confirmed by XPS spectra in Fig. 7 . It's been researched that the $\mathrm{ZnOH}+$ improved alkane aromatization and suppressed the formation of light olefins $[38,39]$. The shift in the binding energy of $\mathrm{Zn}(1021.7$ and $1045 \mathrm{eV})$ and $\mathrm{Fe}(710$ and $725 \mathrm{eV})$ lower and higher energy level respectively from their basic oxides when compared to their binding energies in bimetallic form on ZSM-5 were attributed to inter-metallic bonding and electron balancing on zeolite surface and dispersion of zinc on zeolite matrix as shown from the XRD, SEM and TEM images.

\section{Catalytic performance}

Catalytic conversion of propane was performed at a reaction temperature of $540{ }^{\circ} \mathrm{C}$ and $1 \mathrm{~atm}$. Conversion of propane to aromatics involves a series of reaction steps which include: dehydrogenation of propane to propene, oligomerization of formed alkenes from dehydrogenation, subsequent cracking (alkenes further conversion), new oligomers formation through alkenes alkylation followed by a hydrogen transfer and dehydrogenation, and cyclization and aromatization [6, $23,29,34,40]$. Dehydrogenation of propane is one of most important process of propane aromatization as it begins the reaction steps upon which subsequent reaction depends. It had been established that acidity of dehydrogenating metalmodified ZSM-5 is a vital factor affecting catalytic conversion of alkanes in heterogeneous catalysis reaction and corresponding selectivity towards aromatics [40, 41]. Figure 8 showed the effect of the Iron and zinc loading on parent ZSM-5. Propane conversion on HZSM-5 was high leading to formation of lighter gases and cyclohexane through cracking. Zinc had no much influence on conversion when compared with activity on HZSM-5. The presence of zinc helped in the recombination of surface hydrogen from hydride transfer steps. This occurred (working synergistically with the Bronsted sites of the HZSM-5) in propane dehydrogenation, oligomers and cyclic alkenes and dienes dehydrogenation, thus improving aromatic yield. It had been established in previous researches that aromatization on $\mathrm{Zn} / \mathrm{ZSM}-5$ catalysts occurs mainly via a bifunctional mechanism $[6,23,25$, 27]. The species of zinc present formed the Lewis sites that catalyze the dehydrogenation of propane (activation step) to alkene. Comparing the mechanism of aromatization of propane on acid ZSM-5 and Zn/ZSM-5 (bifunctional catalysts). Zinc prevents the hydride combining with the alkenes to form alkane that is minimized backward hydrogenation reaction. So, this aided the formation of more aromatics $[6$, $9,10,24]$.

Addition of Fe as stabilizing metal increased the activity of the catalysts, which were improved to reasonable extent thereby increasing the conversion of propane significantly. Thus the conversion of the propane was sustained for a longer period of time on stream because the energy level of zinc at the reaction temperature was increased via electron mobility, $\mathrm{Zn}-\mathrm{Fe}$ bimetallic compounding and zinc-iron interaction on ZSM-5 which was determined to enhance its stability. The higher activity in propane conversion after the addition of zinc and iron can be attributed to the increase in

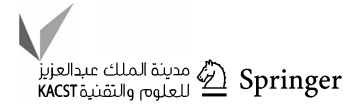


Fig. 7 XPS spectra of a $Z n$ (2p3/2), b Zn of Zn-Fe/ZSM-5 and $\mathbf{c ~ F e}(2 \mathrm{p} 3 / 2)$ of $\mathrm{Zn}-\mathrm{Fe} /$

ZSM-5 catalysts
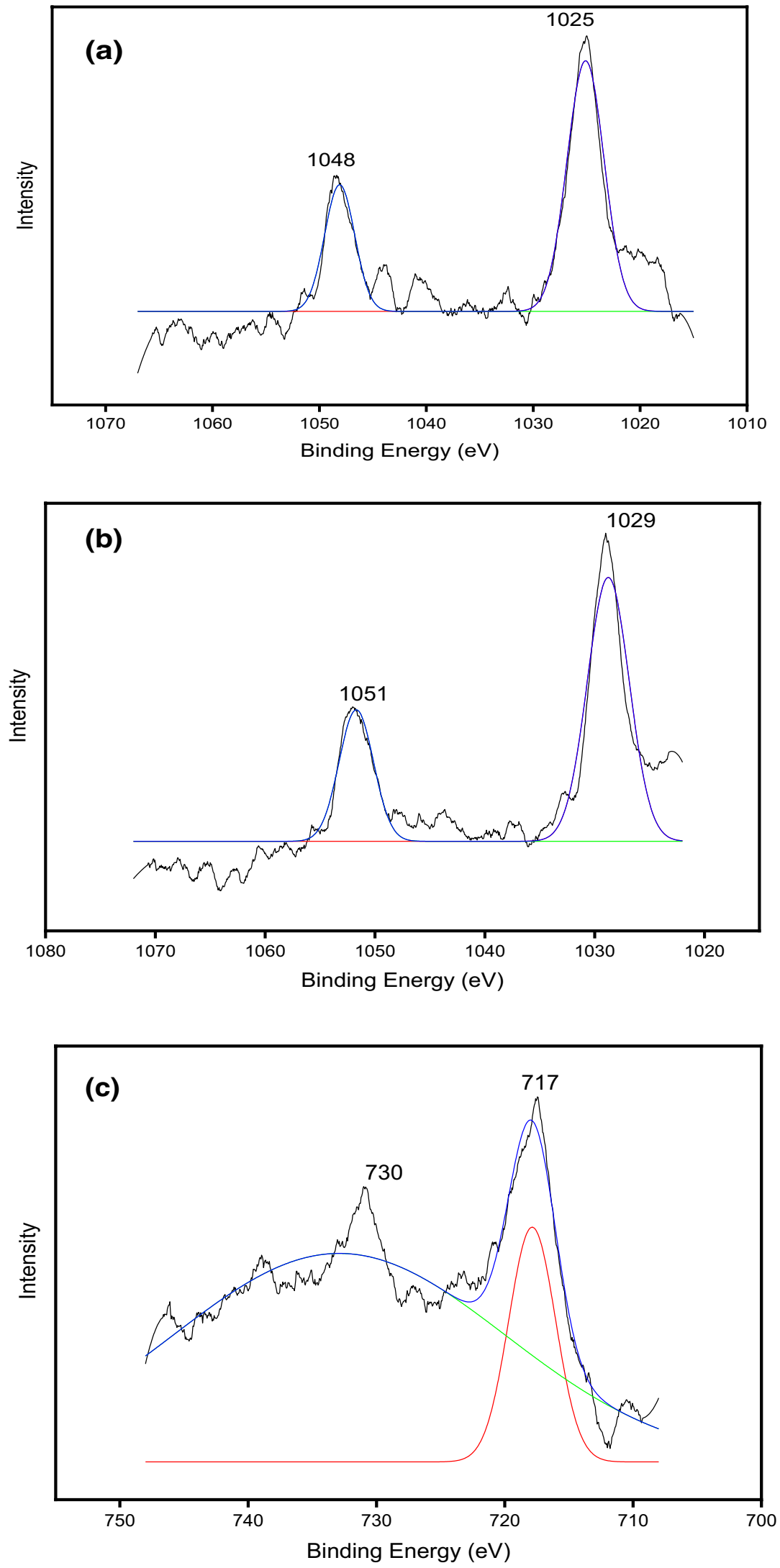


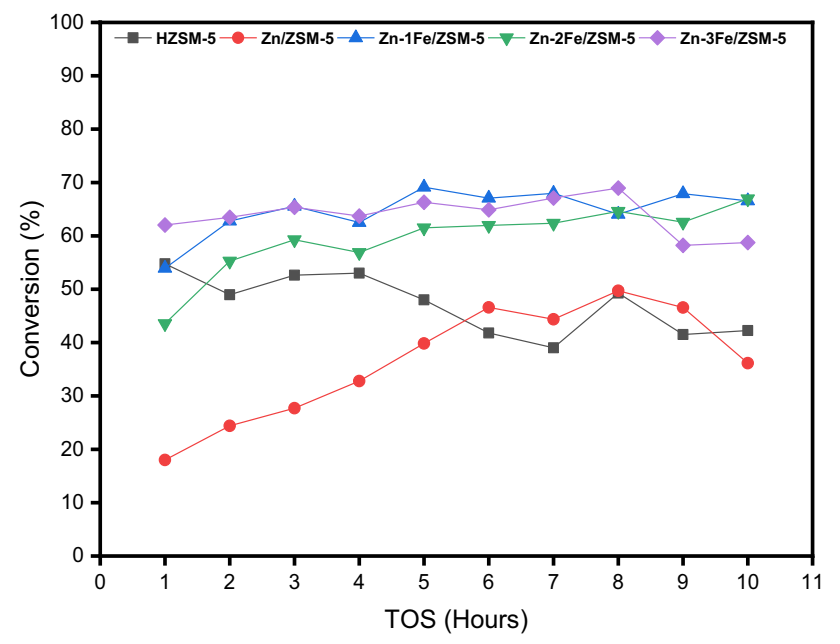

Fig. 8 Propane conversions over ZSM-5 catalysts

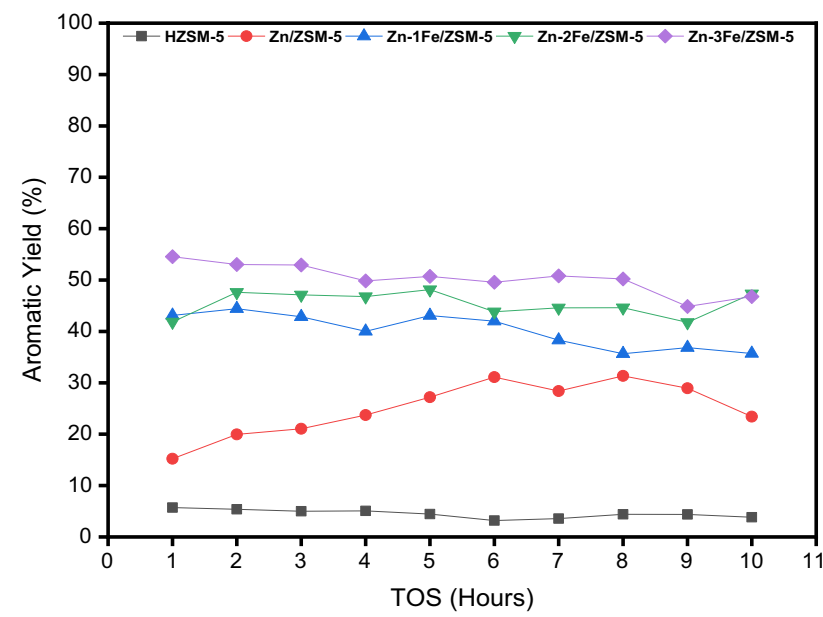

Fig. 9 Aromatic selectivity over ZSM-5 catalysts

dehydrogenation activity due to the presence of $\mathrm{Zn}-\mathrm{Fe}$ bridge species in the H-ZSM-5 channels. This was clearly shown in XPS and $\mathrm{H}_{2}$-TPR by increase in binding energy and reduction temperature as a result of interaction between the $\mathrm{Zn}$ and $\mathrm{Fe}$ species $[23,32,35]$. Also the dehydrogenating effect of zinc metal on zeolite by recombining hydrogen thus suppressing cracking (Beta-scission), minimizing hydrogenation backward reaction and enhancing oligomerization cyclization was enhanced by iron co-impregnation as stabilizing metal over $10 \mathrm{~h}$ time on stream. Zinc instability and deactivation was corrected by sustained and conversion when co-impregnated with 1-3 wt\% iron loading on Zn/ZSM-5. The aromatic yield on Zn-Fe/ZSM-5 catalyst was improved and sustained as compared to only Zn/ZSM-5 (Fig. 9).
The product distributions from propane aromatization using various catalysts prepared and characterized were presented in Figs. 10, 11, 12, 13 and 14. From Fig. 10, the cracking via hydride transfer was obvious as more of lighter alkanes and cyclohexane and lower aromatic compounds were formed [25]. The high dehydrogenating effect of zinc species on HZSM-5 was clearly observed as aromatic products greatly increased with reduced alkane formation in Fig. 11, which included light gases and cyclohexane. Co-impregnation effect of $\mathrm{Zn}$ with $1-3 \mathrm{wt} \% \mathrm{Fe}$ on ZSM-5 was clearly observed in the sustained aromatic product distributions over $10 \mathrm{~h}$ time on stream. In general, light alkanes, cyclohexane and $\mathrm{C}_{9+}$ were greatly reduced in the product distributions in Figs. 12, 13 and 14 as zinc stability, activity and aromatic yield were improved upon thus making more active sites available for dehydrogenation. $1 \mathrm{wt} \% \mathrm{Fe}$ with $\mathrm{Zn}$ produced more ethylbenzene and toluene but reduced benzene among other improved aromatic compounds. Improved toluene would occur via more utilization of formed alkene and methylation of benzene to form more toluene. The formation of ethylbenzene was enhanced via dehydrogenation of formed ethane, which would have further attached to benzene. $2 \mathrm{wt} \% \mathrm{Fe}$ with $\mathrm{Zn}$ on ZSM-5 produced reduced toluene and more of $\mathrm{m}$ and $o$-xylene via methylation of toluene (Fig. 13). Similar trend was observed for $3 \mathrm{wt} \% \mathrm{Fe}$ with $\mathrm{Zn}$ on ZSM-5 but more sustained formation of $\mathrm{m}$ and $o$-xylene (Fig. 14). The higher the Fe content in the catalyst, the more formation of $\mathrm{m}$ and $o$-xylene as observed in Figs. 13 and 14. For all the catalysts, $p$-xylene has little yield as compared to other aromatic products. This may result from the difficulty in the methylation of the carbon in the benzene ring to form 1,4-dimethylbenzene as compared other $m$ and $o$-xylenes that were sequentially arranged as 1,2 and 1,3-dimethylbenzene respectively. The entire improved and sustained aromatic yield recorded were as a result of increased activity of $\mathrm{Zn}$ via co-impregnation with Fe.

\section{Conclusion}

In conclusion, catalytic aromatization of propane was carried out over HZSM-5 supported Zn-Fe/ZSM-5 bimetallic catalysts. All characterizations revealed that the crystallinity and structure of the zeolite were preserved. It was revealed that the presence of $\mathrm{Fe}$ as stabilizing metal enhanced catalyst activity and aromatic yield. The modification had strong influence on activity, aromatic selectivity and product distribution with minimized undesired products. Aromatization 
Fig. 10 Product distribution of propane aromatization over HZSM-5
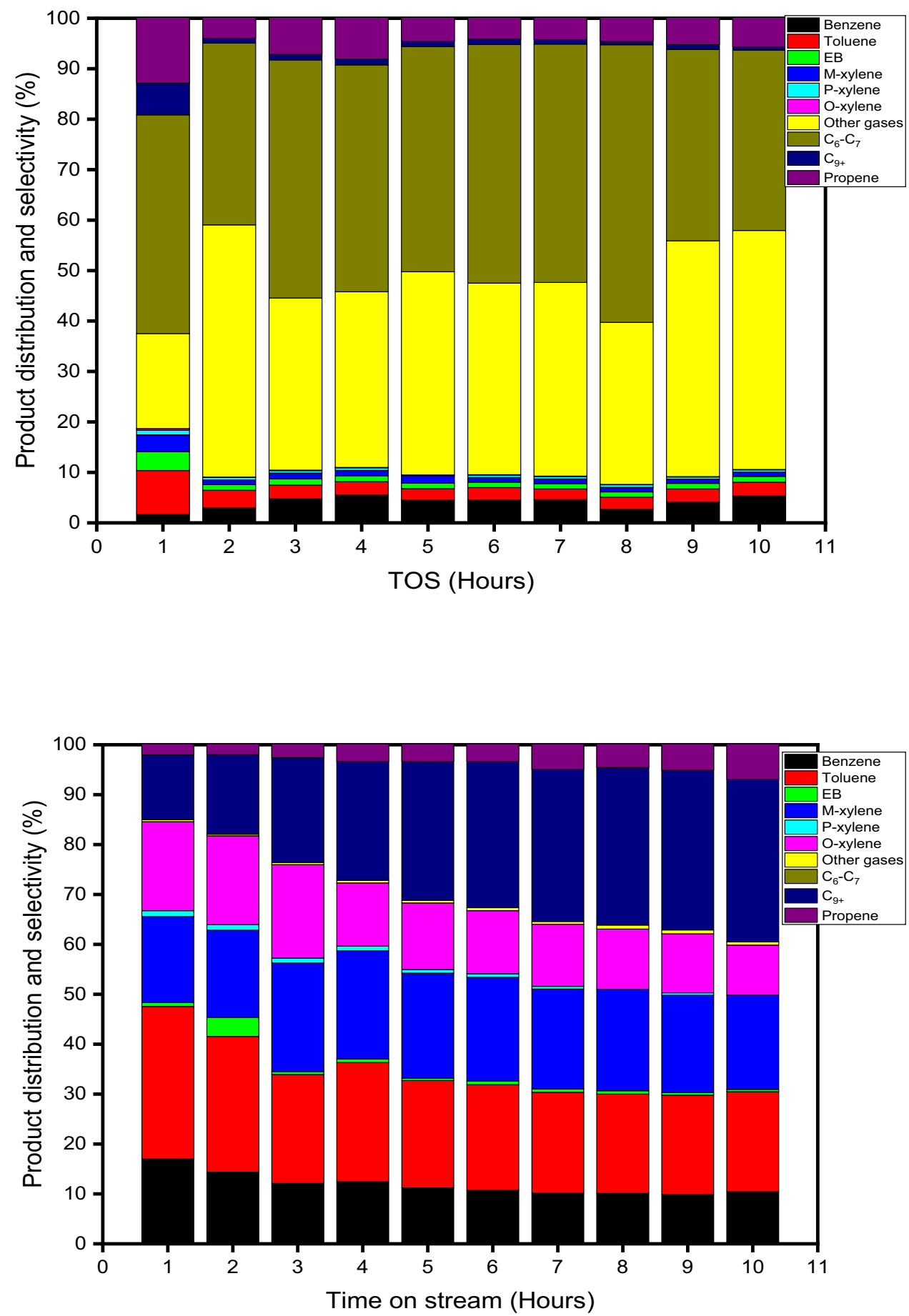

Fig. 11 Product distribution of propane aromatization over $\mathrm{Zn} /$ ZSM-5 reaction path was not altered. This study provided the direct proof of the strengthening ability of the iron second metal as it was clearly shown in the improved and sustained conversion and aromatic yield even at high reaction temperatures.
Furthermore, this developed catalyst will contribute to the development of zeolite based bimetallic industrial catalysts with high activity and superior stability for desired aromatic production. 
Fig. 12 Product distribution of propane aromatization over $\mathrm{Zn}$ 1Fe/ZSM-5

Fig. 13 Product distribution of propane aromatization over $\mathrm{Zn}$ 2Fe/ZSM-5
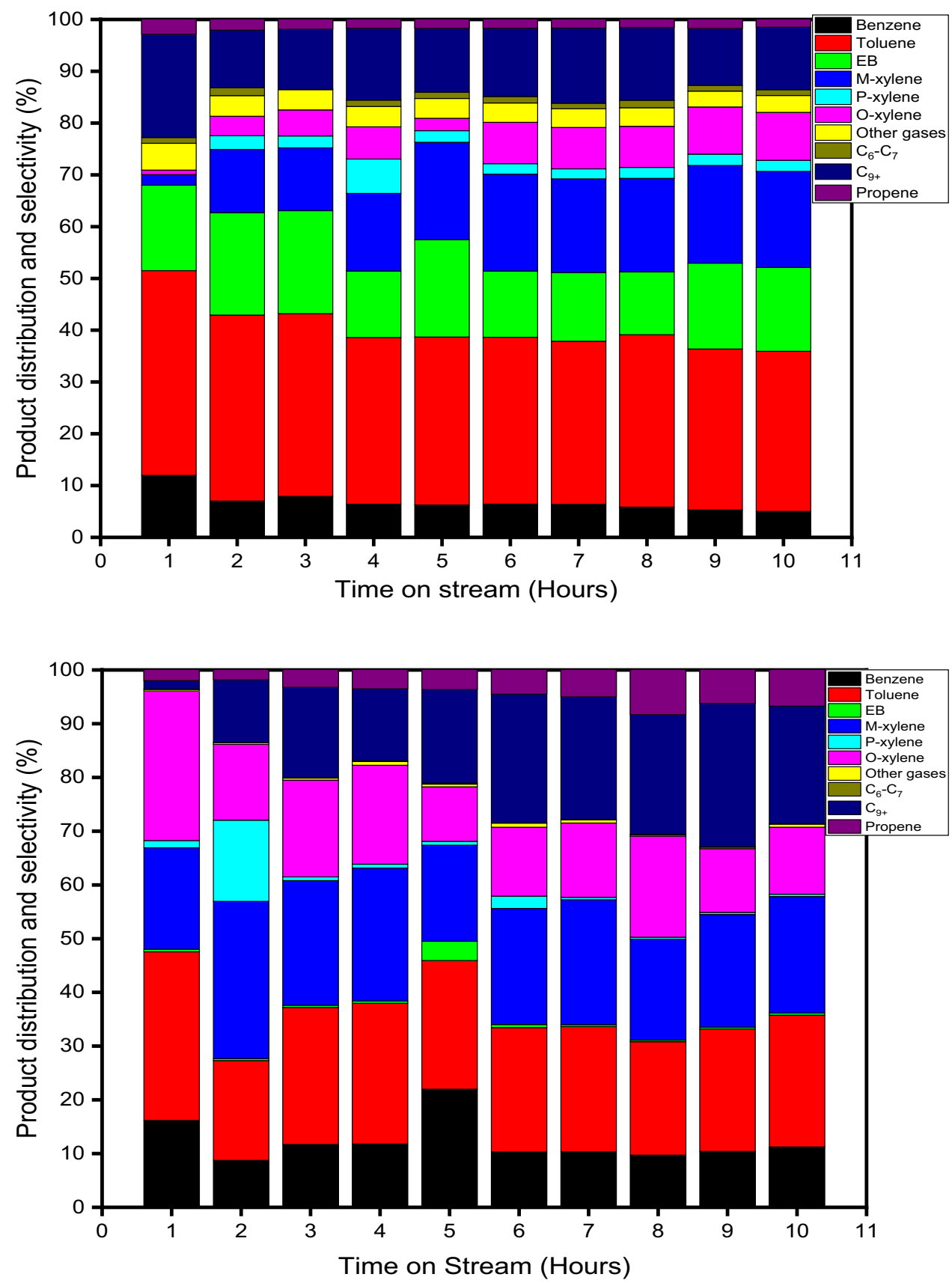
Fig. 14 Product distribution of propane aromatization over Zn-3Fe/ZSM-5

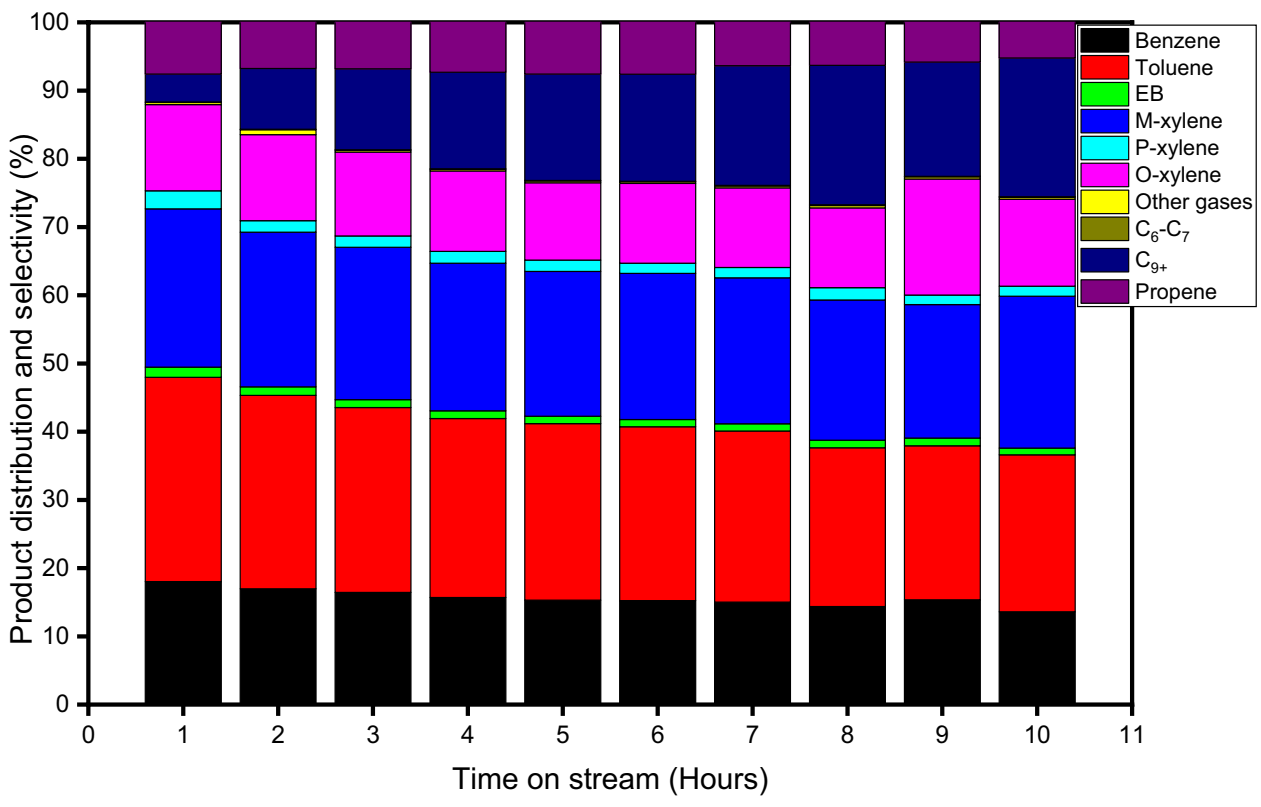

Acknowledgements The authors would like to appreciate Petroleum Technology Development Fund, PTDF, for the fund provided through its annual research grant competition for the execution of this project.

Open Access This article is licensed under a Creative Commons Attribution 4.0 International License, which permits use, sharing, adaptation, distribution and reproduction in any medium or format, as long as you give appropriate credit to the original author(s) and the source, provide a link to the Creative Commons licence, and indicate if changes were made. The images or other third party material in this article are included in the article's Creative Commons licence, unless indicated otherwise in a credit line to the material. If material is not included in the article's Creative Commons licence and your intended use is not permitted by statutory regulation or exceeds the permitted use, you will need to obtain permission directly from the copyright holder. To view a copy of this licence, visit http://creativecommons.org/licenses/by/4.0/.

\section{References}

1. Fechete I, Wang Y, Védrine JC (2012) The past, present and future of heterogeneous catalysis. Catal Today 189(1):2-27

2. Armor JN (2011) A history of industrial catalysis. Catal Today 163(1):3-9

3. Lindström B, Pettersson LJ (2003) A brief history of catalysis. Cattech 7(4):130-138

4. Bhan A, Nicholas Delgass W (2008) Propane aromatization over HZSM-5 and Ga/HZSM-5 catalysts. Catal Rev 50(1):19-151

5. Bhattacharya D, Sivasanker S (1996) Aromatization of $n$-hexane over H-ZSM-5: influence of promoters and added gases. Appl Catal A 141(1-2):105-115

6. Dauda IB, Yusuf M, Gbadamasi S, Bello M, Atta AY, Aderemi BO, Jibril BY (2020) Highly selective hierarchical ZnO/ZSM-5 catalysts for propane aromatization. ACS Omega 5(6):2725-2733

7. Rane N, Overweg AR, Kazansky VB, van Santen RA, Hensen EJM (2006) Erratum to "Characterization and reactivity of Ga+ and $\mathrm{GaO}+$ cations in zeolite ZSM-5" J. Catal. 239 (2) (2006) 478-485]. J Catal 1(240):85
8. Song Y, Xu Y, Suzuki Y, Nakagome H, Zhang ZG (2014) A clue to exploration of the pathway of coke formation on Mo/HZSM-5 catalyst in the non-oxidative methane dehydroaromatization at 1073 K. Appl Catal A 482:387-396

9. Guisnet M, Gnep NS, Aittaleb D, Doyemet YJ (1992) Conversion of light alkanes into aromatic hydrocarbons: VI. Aromatization of C2-C4 alkanes on H-ZSM-5-reaction mechanisms. Appl Catal A Gen 87(2):255-270

10. Choudhary TV, Kinage A, Banerjee S, Choudhary VR (2006) Influence of $\mathrm{Si} / \mathrm{Ga}$ and $\mathrm{Si} / \mathrm{Al}$ ratios on propane aromatization over highly active H-GaAlMFI. Catal Commun 7(3):166-169

11. Brunauer S, Emmett PH, Teller E (1938) Adsorption of gases in multimolecular layers. J Am Chem Soc 60(2):309-319

12. Lippens BC, Linsen BG, De Boer JH (1964) Studies on pore systems in catalysts I. The adsorption of nitrogen; apparatus and calculation. J Catal 3:32-37

13. Liu J, Jiang G, Liu Y, Di J, Wang Y, Zhao Z, Liu J (2014) Hierarchical macro-meso-microporous ZSM-5 zeolite hollow fibers with highly efficient catalytic cracking capability. Sci Rep 4:7276

14. Chu N, Yang J, Li C, Cui J, Zhao Q, Yin X, Wang JJ (2009) An unusual hierarchical ZSM-5 microsphere with good catalytic performance in methane dehydroaromatization. Microporous Mesoporous Mater 118(1-3):169-175

15. Sabarish R, Unnikrishnan G (2019) Synthesis, characterization and evaluations of micro/mesoporous ZSM-5 zeolite using starch as bio template. SN Appl Sci 1(9):989

16. Li Y, Liu S, Xie S, Xu L (2009) Promoted metal utilization capacity of alkali-treated zeolite: Preparation of Zn/ZSM-5 and its application in 1-hexene aromatization. Applied Catalysis A: General 360(1):8-16

17. Wannapakdee W, Suttipat D, Dugkhuntod P, Yutthalekha T, Thivasasith A, Kidkhunthod P, Wattanakit C (2019) Aromatization of C5 hydrocarbons over Ga-modified hierarchical HZSM-5 nanosheets. Fuel 236:1243-1253

18. Van der Borght K, Galvita VV, Marin GB (2015) Ethanol to higher hydrocarbons over Ni, Ga, Fe-modified ZSM-5: Effect of metal content. Applied Catalysis A: General 492:117-126

19. Liu H, Shen W, Bao X, Xu Y (2005) Methane dehydroaromatization over Mo/HZSM-5 catalysts: the reactivity of MoCx species 
formed from MoOx associated and non-associated with Brönsted acid sites. Appl Catal A 295(1):79-88

20. Waziri AY, Osigbesan AA, Dabai FN, Shuwa SM, Atta AY, Jibril BY (2019) Catalytic reforming of gaseous products from pyrolysis of low-density polyethylene over iron-modified ZSM-5 catalysts. Appl Petrochem Res 9(2):101-112

21. Abdelsayed V, Shekhawat D, Smith MW (2015) Effect of Fe and Zn promoters on Mo/HZSM-5 catalyst for methane dehydroaromatization. Fuel 139:401-410

22. El-Shall M, Abdelsayed V, Abd El Rahman SK, Hassan H, ElKaderi HM, Thomas ER (2009) J Mater Chem 19(41):7625-7631

23. Jia Y, Wang J, Zhang K, Feng W, Liu S, Ding C, Liu P (2017) Promoted effect of zinc-nickel bimetallic oxides supported on HZSM-5 catalysts in aromatization of methanol. J Energy Chem 26(3):540-548

24. Mohiuddin E, Mdleleni MM, Key D (2018) Catalytic cracking of naphtha: the effect of Fe and Cr impregnated ZSM-5 on olefin selectivity. Appl Petrochem Res 8(2):119-129

25. Biscardi JA, Meitzner GD, Iglesia E (1998) Structure and density of active $\mathrm{Zn}$ species in $\mathrm{Zn} / \mathrm{H}-\mathrm{ZSM} 5$ propane aromatization catalysts. J Catal 179(1):192-202

26. Chen C, Ji H, Zhang Q, Li C, Shan H (2015) Effect of $\gamma$-alumina as active matrix added to HZSM-5 catalyst on the aromatization of methanol. Appl Petrochem Res 5(4):231-243

27. Mhamdi M, Ghorbel A, Delahay G (2009) Influence of the V+ $\mathrm{Mo} / \mathrm{Al}$ ratio on vanadium and molybdenum speciation and catalytic properties of V-Mo-ZSM-5 prepared by solid-state reaction. Catal Today 142(3-4):239-244

28. Ahmad M, Farhana R, Raman AAA, Bhargava SK (2016) Synthesis and activity evaluation of heterometallic nano oxides integrated ZSM-5 catalysts for palm oil cracking to produce biogasoline. Energy Convers Manag 119:352-360

29. Zhou W, Liu J, Wang J, Lin L, Zhang X, He N, Guo H (2019) Enhancing propane aromatization performance of $\mathrm{Zn} / \mathrm{H}-\mathrm{ZSM}-5$ zeolite catalyst with Pt promotion: effect of the third metal additive-Sn. Catal Lett 149(8):2064-2077

30. Kosinov N, Wijpkema AS, Uslamin E, Rohling R, Coumans FJ, Mezari B, Hensen EJ (2018) Confined carbon mediating dehydroaromatization of methane over Mo/ZSM-5. Angew Chem Int Ed 57(4):1016-1020

31. Mageed AK, Dayang ABR, Salmiaton A, Shamsul I, Musab A (2018) J King Saud Univ Sci
32. Dao TKT, Luu CL (2015) $n$-Hexane hydro-isomerization over promoted Pd/HZSM-5 catalysts. Adv Nat Sci Nanosci Nanotechnol 6(3):035014

33. Yan Y, Jiang S, Zhang H, Zhang X (2015) Preparation of novel Fe-ZSM-5 zeolite membrane catalysts for catalytic wet peroxide oxidation of phenol in a membrane reactor. Chem Eng J 259:243-251

34. Lubango LM, Scurrell MS (2002) Light alkanes aromatization to BTX over Zn-ZSM-5 catalysts: enhancements in BTX selectivity by means of a second transition metal ion. Appl Catal A 235(1-2):265-272

35. Yang YC, Weng HS (2009) The role of $\mathrm{H} 2$ in $n$-butane isomerization over Al-promoted sulfated zirconia catalyst. J Mol Catal A Chem 304(1-2):65-70

36. Roy M, Ghosh S, Naskar MK (2015) Solvothermal synthesis of $\mathrm{Cr}_{2} \mathrm{O}_{3}$ nanocubes via template-free route. Mater Chem Phys 159:101-106

37. Niu X, Gao J, Miao Q, Dong M, Wang G, Fan W, Wang J (2014) Influence of preparation method on the performance of $\mathrm{Zn}$-containing HZSM-5 catalysts in methanol-to-aromatics. Microporous Mesoporous Mater 197:252-261

38. Sapawe N, Jalil AA, Triwahyono S, Sah RNRA, Jusoh NWC, Hairom NHH, Efendi J (2013) Electrochemical strategy for grown $\mathrm{ZnO}$ nanoparticles deposited onto $\mathrm{HY}$ zeolite with enhanced photodecolorization of methylene blue: effect of the formation of SiOZn bonds. Appl Catal A 456:144-158

39. Xiao H, Zhang J, Wang X, Zhang Q, Xie H, Han Y, Tan Y (2015) A highly efficient $\mathrm{Ga} / \mathrm{ZSM}-5$ catalyst prepared by formic acid impregnation and in situ treatment for propane aromatization. Catal Sci Technol 5(8):4081-4090

40. Migliori M, Aloise A, Catizzone E, Caravella A, Giordano G (2017) Simplified kinetic modeling of propane aromatization over Ga-ZSM-5 zeolites: comparison with experimental data. Ind Eng Chem Res 56(37):10309-10317

41. Montes A, Giannetto G (2000) A new way to obtain acid or bifunctional catalysts: V. Considerations on bifunctionality of the propane aromatization reaction over [Ga, Al]-ZSM-5 catalysts. Appl Catal A Gen 197(1):31-39

Publisher's Note Springer Nature remains neutral with regard to jurisdictional claims in published maps and institutional affiliations. 